\title{
Initiating or Blocking Locomotion in Spinal Cats by Applying Noradrenergic Drugs to Restricted Lumbar Spinal Segments
}

\author{
Judith Marcoux and Serge Rossignol \\ Centre de Recherche en Sciences Neurologiques, Faculté de Médecine, Université de Montréal, Montréal, Québec, \\ Canada H3T 1 J4
}

\begin{abstract}
After an acute low thoracic spinal transection (T13), cats can be made to walk with the hindlimbs on a treadmill with clonidine, an $\alpha 2$-noradrenergic agonist. Because previous studies of neonatal rat spinal cord in vitro suggest that the most important lumbar segments for rhythmogenesis are $L 1-L 2$, we investigated the role of various lumbar segments in the initiation of walking movements on a treadmill of adult cats spinalized (T13), 5-6 d earlier. The locomotor activities were evaluated from electromyographic and video recordings. The results show that: (1) localized topical application of clonidine in restricted baths over either the L3-L4 or the L5-L7 segments was sufficient to induce walking movements. Yohimbine, an $\alpha 2$-noradrenergic antagonist, could block this locomotion when applied over L3-L4 or L5-L7; (2) microin-
\end{abstract}

jections of clonidine in one or two lumbar segments from L3 to L5 could also induce locomotion; (3) after an intravenous injection of clonidine, locomotion was blocked by microinjections of yohimbine in segments L3, L4, or L5 but not if the injection was in L6; (4) locomotion was also blocked in all cases by additional spinal transections at L3 or L4. These results show that it is possible to initiate walking in the adult spinal cat with a pharmacological stimulation of a restricted number of lumbar segments and also that the integrity of the L3-L4 segments is necessary to sustain the locomotor activity.

Key words: spinal locomotion; central pattern generator; rhythm generation; midlumbar spinal cord; noradrenergic drugs; electromyography; kinematics
Locomotor activity is largely generated by spinal networks in vertebrates (Grillner, 1981; Rossignol, 1996; Kiehn and Kjaerulff, 1998). This activity is driven by supraspinal commands (Armstrong, 1986) and is modulated by peripheral sensory inputs (Rossignol et al., 1988). Thus, after spinalization in cats, it is possible to reinstate a hindlimb locomotor pattern close to the normal by training (Barbeau and Rossignol, 1987; Edgerton et al., 1992; de Leon et al., 1998) and/or pharmacological stimulation (Rossignol, 1996; Rossignol et al., 1998, 2000).

Early studies showed that acute spinal cats could generate fictive locomotion after an intravenous injection of L-DOPA (Jankowska et al., 1967a,b; Grillner and Zangger, 1979) and stepping on a treadmill with the $\alpha_{2}$-noradrenergic agonist clonidine (Forssberg and Grillner, 1973; Barbeau and Rossignol, 1987).

In the above studies, the drugs were administered either intravenously or intraperitoneally and thus were distributed to various levels of the spinal cord. Clonidine or noradrenaline injected intrathecally is also efficient (Kiehn et al., 1992; Chau et al., 1998b). In an attempt to better understand where these drugs act on the spinal cord we have studied the effects on locomotion of application at restricted lumbar segments of clonidine and yohimbine, a specific $\alpha_{2}$-noradrenergic antagonist (Goldberg and Robertson, 1983).

There are two current models of the lumbosacral distribution of locomotor networks based on neonatal rat spinal cord in vitro preparation. In one model, it is suggested that the locomotor drive is limited to L1-L2 segments from where it is distributed to motoneurons (Cazalets et al., 1995). In the other model, the networks are distributed along the lumbosacral cord with the rostral segments leading the others (Kjaerulff and Kiehn, 1996). These networks may have different localization (including su-

\footnotetext{
Received Aug. 1, 2000; revised Aug. 22, 2000; accepted Aug. 29, 2000.

This work was supported by a grant from the Christopher Reeve Paralysis Foundation and the Canadian Medical Research Council. We would like to acknowledge the essential contribution of Janyne Provencher, France Lebel, Claude Gagner, Philippe Drapeau, and Claude Gauthier. Many thanks to Dr. J.-P. Gossard and H. Leblond for their help with some of the experiments.

Correspondence should be addressed to Dr. Serge Rossignol, Centre de Recherche en Sciences Neurologiques, Pavillon Paul-G.-Desmarais, 2960 Chemin de la Tour, Université de Montréal, Montréal, Québec, Canada H3T 1J4. E-mail: Serge. Rossignol@umontreal.ca.

Copyright (C) 2000 Society for Neuroscience $0270-6474 / 00 / 208577-09 \$ 15.00 / 0$
}

pralumbar segments), depending on which neurotransmitter is used (Cowley and Schmidt, 1997). It is also unknown if this organization of rhythm generation in immature animals remains the same in adulthood. Earlier experiments in acutely spinalized adult cats suggested that even the isolated caudal segments (L6-L7-S1) (Grillner and Zangger, 1979) could produce right-left alternating rhythm. Another study with adult cats using a cooling probe applied on the spinal cord to disable momentarily one or two segments at a time, also reported that the rhythm generation ability for scratching was distributed along the spinal cord with the L3-L5 segments being the most important (Deliagina et al., 1983).

Because our previous work has shown that noradrenergic drugs can trigger or block spinal locomotion when applied intrathecally or intravenously, we have used the same drugs to initiate or block spinal rhythms by focal applications in baths or microinjections. A better knowledge of the relative importance of various spinal segments would be crucial to improve stimulation strategies (electrical or pharmacological) for recovery of locomotion in spinal cord injured humans (Dimitrijevic et al., 1998) and also limit the adverse effects of drugs injected systemically.

\section{MATERIALS AND METHODS}

Twenty-four cats of either sex $(2.1-5.8 \mathrm{~kg}$ ) were used for this study. They were spinalized 4-6 d before the acute experiment, except for two cats that were spinalized on the day of the experiment. All procedures were conducted according to the Guide for the Care and Use of Experimental Animals (Canada), using protocols approved by the Ethics Committee of Université de Montréal.

Spinalization. All surgeries were performed in aseptic conditions and under general anesthesia. Anesthesia with isoflurane $2 \%$ was induced by mask after a preoperative medication [acepromazine maleate (Atravet), $0.1 \mathrm{mg} / \mathrm{kg}$, i.m.; glycopyrrolate, $0.01 \mathrm{mg} / \mathrm{kg}$, i.m.; and ketamine, $10 \mathrm{mg} / \mathrm{kg}$, i.m.]. After endotracheal intubation, a laminectomy was performed at the T13 vertebra. The dura was carefully opened, a few drops of xylocaine $(2 \%)$ was applied on the spinal cord, and a few injections were made directly into the spinal cord at the T13 level. The spinal cord was severed completely with a pair of surgical scissors so that the ventral surface of the spinal cord could be clearly visualized. Absorbable hemostat (Surgicel) was then used to fill up the space between the rostral and caudal ends of the spinal cord, thus helping hemostasis before suturing the wound in layers. In some cases a patch of transdermal fentanyl (Duragesic*25) was sutured to the skin below the level of the spinal lesion. A bladder catheter was inserted in some cases and then sutured to the perineum.

Postoperative care. After the surgery, the animal was placed in a heated 


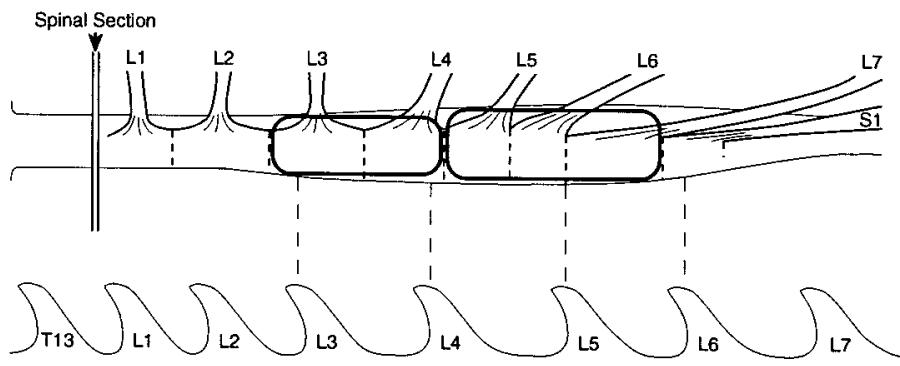

Figure 1. Schematic representation of the spinal cord after the laminectomy. The two vertical lines at the left represent the level of the first spinalization (T13). The longitudinal limits of the bath are shown with bold lines, and each segment is separated by dotted lines. At the bottom the corresponding spinous processes are represented.

incubator until it regained consciousness and was then returned with ample food and water to its individual cage $(104 \times 76 \times 94 \mathrm{~cm})$ lined with a foam mattress in addition to absorbent tissues. The animal was attended to at least twice daily for manual bladder expression if no catheter was in place, for general inspection, and for cleaning the hindquarters. Analgesia for the first 3 postoperative days was ensured by the fentanyl patch $(2.5 \mathrm{mg}, 25$ $\mu \mathrm{g} / \mathrm{hr}$ for $72 \mathrm{hr})$ or by buprenorphine hydrochloride administration $(0.01$ $\mathrm{mg} / \mathrm{kg}$, s.c. every $6 \mathrm{hr}$ ).

Acute experiments. Under general anesthesia (see Spinalization for details) and endotracheal intubation or tracheotomy, one carotid artery was cannulated for monitoring blood pressure, and one jugular vein was cannulated for the administration of fluid and medication. The temperature was measured with a rectal thermometer and maintained at $\sim 38^{\circ} \mathrm{C}$ by a feedback-controlled heating element using direct current and with heating lamps. The end-expiratory $\mathrm{pCO}_{2}$ was maintained between 3.5 and $4.5 \%$ using a Datex Monitor during normal or assisted ventilation. Most cats $(n=19)$ were decerebrated anemically by ligature of the common carotid arteries and the basilar artery just cranial to the branch point of the posterior inferior cerebellar arteries (Pollock and Davis, 1923) through an opening hole at the base of the skull with a dental drill; the other cats $(n=$ 5 ) were decerebrated by a precollicular, postmammillary transection and removal of the rostral parts of the brain. Anesthesia was discontinued afterward.

The cat was then mounted in a frame attached to a motor-driven treadmill, and the spine was fixed with three pairs of lateral pins, including one at the iliac crest. A laminectomy was performed from L2 to L7. The two cats with spinal cord intact were spinalized at T13 through a smaller laminectomy at that level. All cats were first tested for locomotion with only saline solution or warm mineral oil covering the spinal cord after the dura has been opened but without any drug. The spinal segments (Fig. 1) were determined by identifying the most rostral and the most caudal dorsal rootlets.

Drug delivery. The pharmacological agents were then applied in two ways: (1) In 10 cats, a pool encircling L2 to L7 dorsal surface with walls 1 to 2-mm-thick was constructed using petroleum jelly and soft dental polymer with a barrier built at the L4-L5 junction (1- to 2-mm-thick), resulting in an L3-L4 bath and an L5-L7 bath as schematized in Figure 1. The integrity of a particular bath was assessed using coloring or Fast green dye or by draining all spaces surrounding it, convincing us that there was no leak. A selected bath was filled with the drug of interest (clonidine $5 \mathrm{mg} / \mathrm{ml}$ or yohimbine $8-16 \mathrm{mg} / \mathrm{ml})(\sim 250 \mu \mathrm{l})$ or saline solution, and the rest of the spinal cord was covered with warm mineral oil. The sequence and number of baths and the drug used varied from one experiment to the other. When changing one drug to the other, the bath was first thoroughly washed with saline solution. Also when a drug was applied, it was regularly washed and reapplied to make sure that its effect did not fade with evaporation and time (effects of clonidine applied intrathecally usually last for 3-4 hr). (2) In 12 cats, drugs (clonidine $10 \mathrm{mg} / \mathrm{ml}$ or yohimbine $8 \mathrm{mg} / \mathrm{ml}$ ) were microinjected intraspinally ( $2 \mu \mathrm{l} /$ injection) using a Hamilton syringe (26 gauge needle) (Hamilton, Reno, NV) inserted 2-mm-deep paramedially (1 mm on each side of the midline) in the segment L3, L4, L5, L6, and/or L7, while the spinal cord was covered with warm mineral oil. The injections at 2-mm-deep correspond to approximately half of the thickness of the cord. The target was the gray matter at around the depth of the central canal. Eight to 10 injections were made per segment to cover the whole segment bilaterally. The diffusion of the injected material was assessed in two experiments adding Fast green dye to the solution to be injected. The dye did not extend beyond a diameter of $1 \mathrm{~mm}$. There also is the concern that the spinal cord could be damaged by the injections. However, the spinal cord pathways always remained reactive in response to painful stimuli or muscle stretching. Also, we performed the lesions with the help of an operating microscope to avoid vessels and verify in every case that the microcirculation of the spinal cord appeared normal at all times.

Clonidine was used because the noradrenergic system is probably the most important system for initiating locomotion in cats (Barbeau and Rossignol, 1991; Rossignol, 1996; Chau et al., 1998b). The intraperitoneal or intravenous doses of clonidine traditionally used in acute spinal cats varied between 200 and $500 \mu \mathrm{g} / \mathrm{kg}$ (Forssberg and Grillner, 1973; Barbeau et al., 1987), which corresponds to giving $1 \mathrm{ml}$ of a $19 \mathrm{~mm}$ solution to cats. For baths, we applied $\sim 250 \mu$ l of a solution with the same concentration. For microinjections, the concentration was doubled $(38 \mathrm{~mm})$, but only 16-20 $\mu$ l were injected per segment. Yohimbine was used for its specificity to block $\alpha_{2}$-noradrenergic receptors, although at high concentrations, yohimbine can interact with serotonin and dopamine receptors (Goldberg and Robertson, 1983). It could thus be possible that, at the concentration used, yohimbine might have blocked some other receptors, but neither for clonidine nor for yohimbine did we investigate the optimal dose.

All cats eventually received an intravenous injection of clonidine $(500$ $\mu \mathrm{g} / \mathrm{kg}$ ) and sometimes also methyl-L-DOPA (80 mg/ $\mathrm{kg}$ ) after the localized bath application or microinjections of drugs. Methyl-L-DOPA is analogous to L-DOPA and can be easily dissolved in water (Bras et al., 1988). In nine cats the effect of additional spinalization at the caudal end of L3 and sometimes also at the caudal end of L4 on the locomotor pattern was tested.

Recordings and analyses. The locomotor capabilities of the cat were evaluated on a treadmill at a speed of $0.3 \mathrm{~m} / \mathrm{sec}$ while using perineal and/or abdominal manual stimulation. The muscles were implanted percutaneously (21 gauge needles) with pairs of enamel-insulated copper wires in selected flexor muscles (semitendinosus, sartorius anterior, and tibialis anterior) and extensor muscles (vastus lateralis and gastrocnemius lateralis) to record electromyographic (EMG) activities. Reflective markers were placed on the bony landmarks of the hindlimb: the iliac crest (the marker was thus on one of the lateral pin and fixed relative to the frame), the femoral head, the knee joint, the lateral malleolus, the metatarsophalangeal joint, and the tip of the third toe.

Video images of the locomotor movements were captured by a digital camera (Panasonic 5100; shutter speed 1/1000 sec) and recorded on a video recorder (Panasonic AG 7300). The EMG signals were amplified with AC-coupled amplifiers (bandwidth of $300 \mathrm{~Hz}$ to $10 \mathrm{kHz}$ ), recorded on a Honeywell tape recorder (model 101) with a frequency response of $0-2500$ $\mathrm{kHz}$ at the recording speed of $9.5 \mathrm{~cm} / \mathrm{sec}$ and on-line digitized at $1 \mathrm{kHz}$ with a custom-made software. The EMG recording was synchronized to the recorded video images by means of a digital Society for Motion Picture and Television Engineers time code. This time code was recorded simultaneously on the EMG tape and was superimposed on the video images themselves.

The onset and offset of the bursts of activity in muscles were detected first automatically then verified and corrected manually when necessary. On playback, the EMG recordings were set to have the same amplification throughout the experiment. Video images were digitized using a twodimensional PEAK Performance system (Peak Performance Technologies, Englewood, CA). Displacement data, encoded by the $x$ and $y$ coordinates of different joint markers were measured at 60 fields/sec (temporal resolution of each image is therefore $16.7 \mathrm{msec}$ ). Angular displacement data and joint angles also were calculated automatically (e.g., hip joint angle was calculated based on the relative position of the iliac, hip, and knee markers). From both $x-y$ coordinates of the recorded markers, displacement data, and the calculated joint angle data, displays of stick diagrams or trajectories were generated using custom-made software. Stick diagram of one step cycle consisted of reconstruction of the actual hindlimb movement during the stance and swing phases.

A complete step cycle consists of a stance and a swing phases. The stance phase begins as soon as the foot contacts the supporting surface, in this case the treadmill belt, and terminates when the foot starts its forward movement. The swing phase begins at the onset of the forward movement and terminates as the foot strikes the treadmill belt again. Foot drag is commonly seen after spinalization, resulting from an inadequate clearance of the foot during swing, and is defined as the initial period during which the dorsum of the paw touches the treadmill during the forward movement of the foot. Step cycle duration was defined as the time elapsed between successive contacts of the same foot. The angles were calculated by the Peak Performance calculation program, which generated the angular displacement data. The normalized EMG amplitude is obtained by dividing the integrated value of the whole burst by its duration. The values of interlimb coupling correspond to the phase value of the onset of semitendinous burst relative to the onset of the semitendinous burst in the other limb.

\section{RESULTS}

In all experiments, we first assessed locomotor capabilities of the hindlimbs of spinalized cats over the treadmill with perineal and abdominal stimulation before applying any pharmacological agent. Afterward, we evaluated the response to drugs applied either in baths restricted to a few segments of the cord or with intraspinal microinjections. After these localized drug applications, we sought to induce long-lasting walking sequences with systemic intravenous injections of drugs (clonidine or DOPA), and we tested, with successive lesions at L3 and L4, the importance of these rostral segments on the generation of walking movements of the hindlimbs when drugs are applied systemically. 


\section{Locomotor capacities before pharmacological stimulation}

All 24 decerebrated acutely spinalized and fixed cats were tested over the treadmill with perineal and abdominal stimulation before the application of drugs. None of them showed locomotor activity of the hindlimbs or rhythmic EMG patterns even a few hours after decerebration. Spinal reflexes were almost always present (e.g., ipsilateral flexion along with controlateral extension of the hindlimbs when a noxious stimulus was applied), and most often perineal stimulation could elicit bilateral tonic flexion of the hindlimbs but no rhythmic movements.

\section{Bath-applied drugs}

We tried to induce locomotion initially by applying drugs either over the proximal bath (L3-L4) or over the distal bath (L5-L7) for the first experimental condition. Then we looked for possible interactions between the various levels by applying different kinds of drugs in different sequences in both baths. Thus, we could assess synergistic effects by applying the agonist in the two baths or antagonistic effects by applying the agonist and the antagonist in different baths.

The effect on locomotor initiation of clonidine as first applied in a bath overlying L3 and L4 segments was tested in seven cats. Locomotion was initiated in four cats, and one is illustrated in Figure 2. As mentioned before, note that in the control predrug period (Fig. $2 A$ ) there is no movement whatsoever despite strong perineal and abdominal stimulation. Figure $2 B$ (top) shows a typical example of the movements induced by bath application of clonidine combined with such perineal and/or abdominal skin stimulation provided by the experimenter. These movements were clearly locomotor in nature (frequency, kinematics), but also they were deficient given the imposed constraints such as an extensive laminectomy and the pins used for fixation. A typical step cycle can be described as follows. The foot dragged on the belt before being lifted well above ground. After swing, the foot landed on the dorsum, and a weak but clear extension followed. The step length was smaller than in normal cats, and the limb would not always follow the treadmill speed. Typically, a sequence of $8-15$ consecutive steps could be initiated, after which the cat stopped. The same sequence could be repeated after a few minutes of rest, again with perineal stimulation. The bottom part of Figure $2 B$ illustrates the simultaneously recorded EMG pattern. This activity alternates on the left (L) and right (R) sides as well as between flexors (e.g., RSt) and extensors (e.g., RGL) on each side. Of the three remaining cats, one did show a similar pattern but only after the addition of clonidine in the L5-L7 bath. The two others never displayed any rhythmic activity despite clonidine at L5-L7 or systemic application of clonidine or L-DOPA intravenously later on.

In the cat displayed in Figure $2 B$, we also applied the $\alpha-2$ adrenergic blocker in the same bath overlying L3-L4 (Fig. 2C). Yohimbine was applied 2 hr 14 min after the beginning of clonidine application, which was regularly washed and reapplied every 30-45 min to prevent evaporation and degradation of the drug to make sure that locomotion was indeed well present before applying yohimbine and that the disparition of that locomotion was not caused by an insufficient amount of stimulating agent. After yohimbine, only tonic contractions without any rhythmic activity were observed in both hindlimbs. The yohimbine was washed after $1 \mathrm{hr}$ $20 \mathrm{~min}$, and clonidine was reapplied in the same bath. The initial rhythmic pattern reappeared $16 \mathrm{~min}$ after the exchange of drugs. This sequence was repeated once more, and the same results were obtained. Only this cat was tested with yohimbine at L3-L4 with clonidine application only at L3-L4. Overall then, these results clearly suggested that it was possible to induce a full pattern of locomotor movements that involved even distal muscles such as GL, an ankle extensor, with a restricted application of drugs at L3-L4.

Clonidine was also first applied on L5-L6-L7 segments in three cats. Two of them showed stepping movements and well organized rhythmic EMG activity with left-right and flexor-extensor alterna-
A

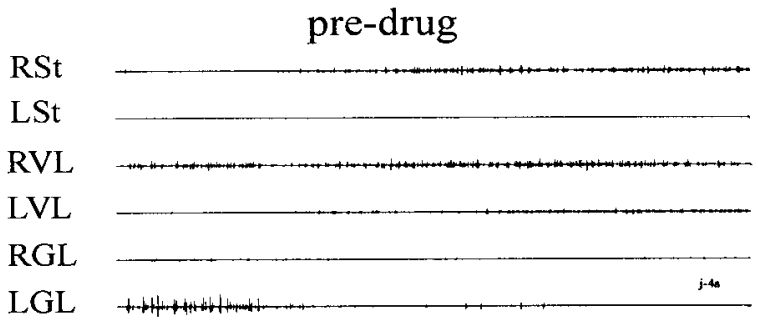

B

\section{Clonidine L3-L4}
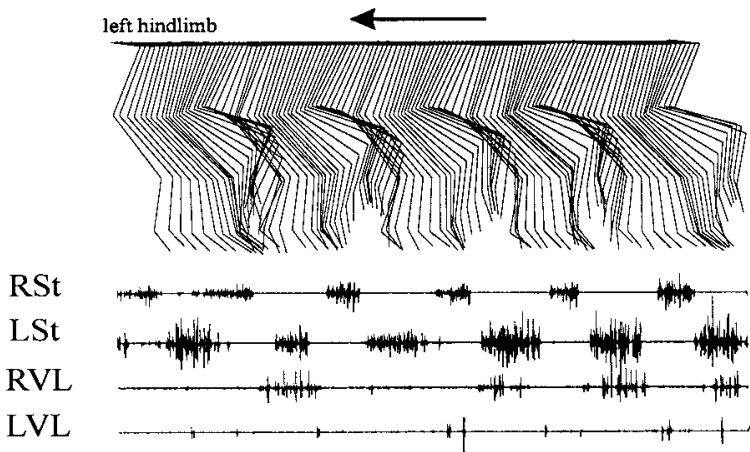

RGL

LGL

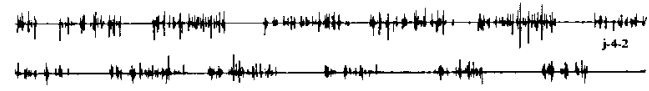

$\mathrm{C}$

Yohimbine L3-L4

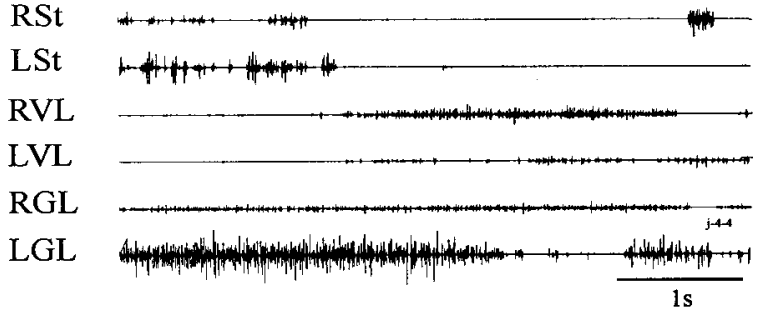

Figure 2. Drugs applied in a bath at L3-L4. A, Predrug. B, Top, The stick figures represent five consecutive cycles (stance and swing phases) of the left hindlimb and (middle) the related EMG of both hindlimbs $2 \mathrm{hr}$ after clonidine $(5 \mathrm{mg} / \mathrm{ml})$ application. $C$, Hindlimb EMGs $1 \mathrm{hr} 15 \mathrm{~min}$ after clonidine washing and yohimbine $(8 \mathrm{mg} / \mathrm{ml})$ application in the same cat. $R S t$, Right semitendinosus; $L S t$, left semitendinosus; $R V L$, right vastus lateralis; $L V L$, left vastus lateralis; $R G L$, right gastrocnemius lateralis; $L G L$, left gastrocnemius lateralis. Note that the gains and displays for all EMGs of the corresponding muscles in $A$ and $B$ were adjusted to provide the same final amplification.

tion. One of the two cats is illustrated in Figure $3 A$. The steps were similar to those described when clonidine was applied at L3-L4 (Fig. 2B). Here also, there was a foot drag, and the steps were insufficient to adequately follow the treadmill speed. In the third cat, only tonic activity was induced, and there was no improvement with the addition of clonidine at L3-L4. This cat however did display a few unsustained stepping movements after an intravenous injection of clonidine.

After applying drugs in one bath, the effects of drugs applied in the other bath was assessed. When the first bath of clonidine was over L3-L4, the addition of clonidine over L5-L7 improved the stepping pattern in one cat, that is the stance phase became longer and stronger. Corresponding changes were seen on EMG with an increase in amplitude and duration of extensor bursts (data not shown). In one other cat, the additional application of clonidine to the L5-L7 segments induced a stepping pattern where one was not present before. That example is shown in Figure $3, B$ and $C$. In Figure $3 B$, in which only L3-L4 segments were covered with clonidine, some weak rhythmicity can be seen. In Figure $3 C$ a locomotor rhythmic pattern associated with stepping on the treadmill appeared. The remaining four cats did not improve with the 
A

\section{Clonidine L5-L7}

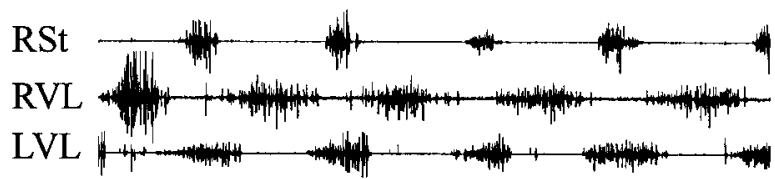

RGL

RSrt

LSrt

LTA

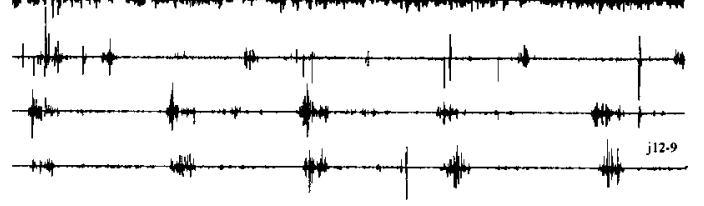

B

Clonidine L3-L4

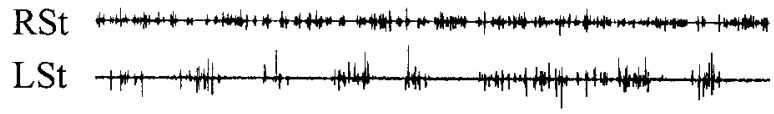

RVL

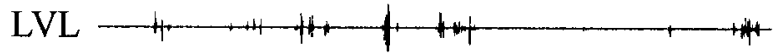

RGL LGL

C

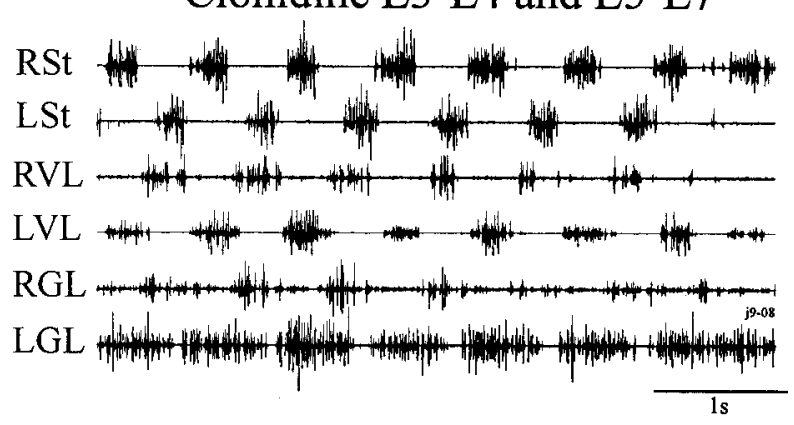

Figure 3. Clonidine applied in a bath at L5-L7. A, Hindlimb EMGs $1 \mathrm{hr}$ $48 \mathrm{~min}$ after clonidine $(5 \mathrm{mg} / \mathrm{ml})$ application in the L5-L7 bath. $B$, Hindlimb EMGs of another cat $2 \mathrm{hr}$ after clonidine in the L3-L4 bath. $C$, Hindlimb EMGs 31 min after clonidine in L5-L7 bath as well. The EMG became better defined and the rhythm more regular. $R S r t$, Right sartorius anterior; $L S r t$, left sartorius anterior; $L T A$, Left tibialis anterior.

addition of clonidine over L5-L7 bath; two kept the same imperfect walking pattern, and two did not walk. Table 1 summarizes the sequence and effects of clonidine application.

In a number of experiments we have tried to evaluate the importance of some segments in maintaining the locomotor activity induced by other segments. Thus, the effect of yohimbine was tested in one bath after the induction of a locomotor rhythm by clonidine in the other bath. Figure $4 A$ shows a well organized locomotor rhythm that was induced by a clonidine application in the L5-L7 bath. Fifteen minutes after applying yohimbine in the L3-L4 bath (Fig. 4B), it became impossible to elicit locomotion with the same perineal stimulation that had been effective for a period of $\sim 90 \mathrm{~min}$ before. These results were also found in one other cat in which the converse strategy was used. In Figure $4 C$, locomotion induced by clonidine applied at L3-L4 bath in the same cat was blocked by the addition of yohimbine at L5-L7 bath (Fig. 4D). This was also tested in one other cat and yielded the same results.

The above observations are compatible with the idea that a widespread locomotor pattern presumably recruiting motoneurons located throughout the lumbosacral spinal cord could be generated
Table 1. Effects of clonidine applied to baths at different levels on the spinal cord or after intravenous injection

\begin{tabular}{llll} 
Clonidine & & L3-L4 & L5-L7 \\
\hline First application in & Initiation of walk & $4 / 7$ & $2 / 3$ \\
the bath & No walk & $3 / 7$ & $1 / 3$ \\
Application in the & Same quality of walk & $3 / 7$ & $2 / 3$ \\
second bath after & Improved quality of walk & $1 / 7$ & \\
application in the & Initiation of walk & $1 / 7$ & \\
first & No walk & $2 / 7$ & $1 / 3$ \\
& Same quality of walk & $3 / 7$ & $2 / 3$ \\
\multirow{2}{*}{$\begin{array}{l}\text { Addition of an intra- } \\
\text { venous injection }\end{array}$} & Improved quality of walk & $2 / 7$ & \\
& Initiation of walk & & $1 / 3$ \\
\hline
\end{tabular}

by applications of clonidine at restricted levels of the cord (L3-L4) or (L5-L7). Furthermore, these results suggested that the widespread locomotor pattern initiated by stimulating one level could be blocked by the restricted application of yohimbine at another level. This led to the experiments described in the next section in which localized intraspinal microinjections were used to insure that the above results were not attributable to a spread of the drugs across the polymer-vaseline barriers.

\section{Intraspinal microinjections Clonidine}

Intraspinal microinjections were performed in 12 cats. In three cats, when clonidine was injected intraspinally only at L3 and L4, a clear pattern of locomotion was induced with a good alternation between homologous muscles of the right and the left hindlimbs and with a reciprocal activation of flexor and extensor muscles, resulting in clear stepping movements on the treadmill. Figure 5A shows that one of these cats even demonstrated a slow locomotor rhythm and stepping after only the L3 segment was injected. This rhythm appeared within $12 \mathrm{~min}$ after the last injection at that level. Figure $5 B$ shows the same cat after further injections at L4. Note that the step cycle frequency is almost doubled and that several other muscles are now clearly activated compared with Figure $5 A$. This pattern appeared within 14 min after the last injection. Figure $5 B^{\prime}$ shows the stick figures, the averaged EMG recordings, and the averaged joint angular displacement of the sequence displayed in Figure $5 B$. Figure $5 C$ shows again the same cat but when clonidine was added intravenously. Note that the cycle duration is not changed, nor is the amplitude of the EMG, but the bursts are somewhat better defined. Therefore, it appears that in this case the locomotor pattern had been recruited almost maximally by the local L3-L4 injections. Table 2 compares cycle duration and muscle contraction duration and amplitude when clonidine was injected at L3, L3-L4, or intravenously.

Microinjections in L5 alone were tried in three cats. The first cat showed slow rhythm similar to those observed with L3 injection, except that muscle contractions were not strong enough to induce measurable movements. The addition of microinjections in L6 segment strengthened a little the contractions in this cat. Further injections in L7 segment improved even more the locomotor pattern. In the second cat, injections in L5 brought the same weak muscle contractions seen with the first cat, and additional injections in L6 segment did not modify them significantly. In the last cat, microinjections in L5 segment failed to produce locomotion, but addition of injections in L6 segment initiated locomotion in one of the two cats that showed rhythm with injections into only the L5 segment. Microinjections of only the L6 segment were also tried in one cat and gave slow rhythm without clearly measurable steps. Additional microinjections of the L7 segment hardly improved the rhythmic pattern, but further microinjections in the L5 segment induced strong stepping.

Of the five cats that did not show locomotor activity after 

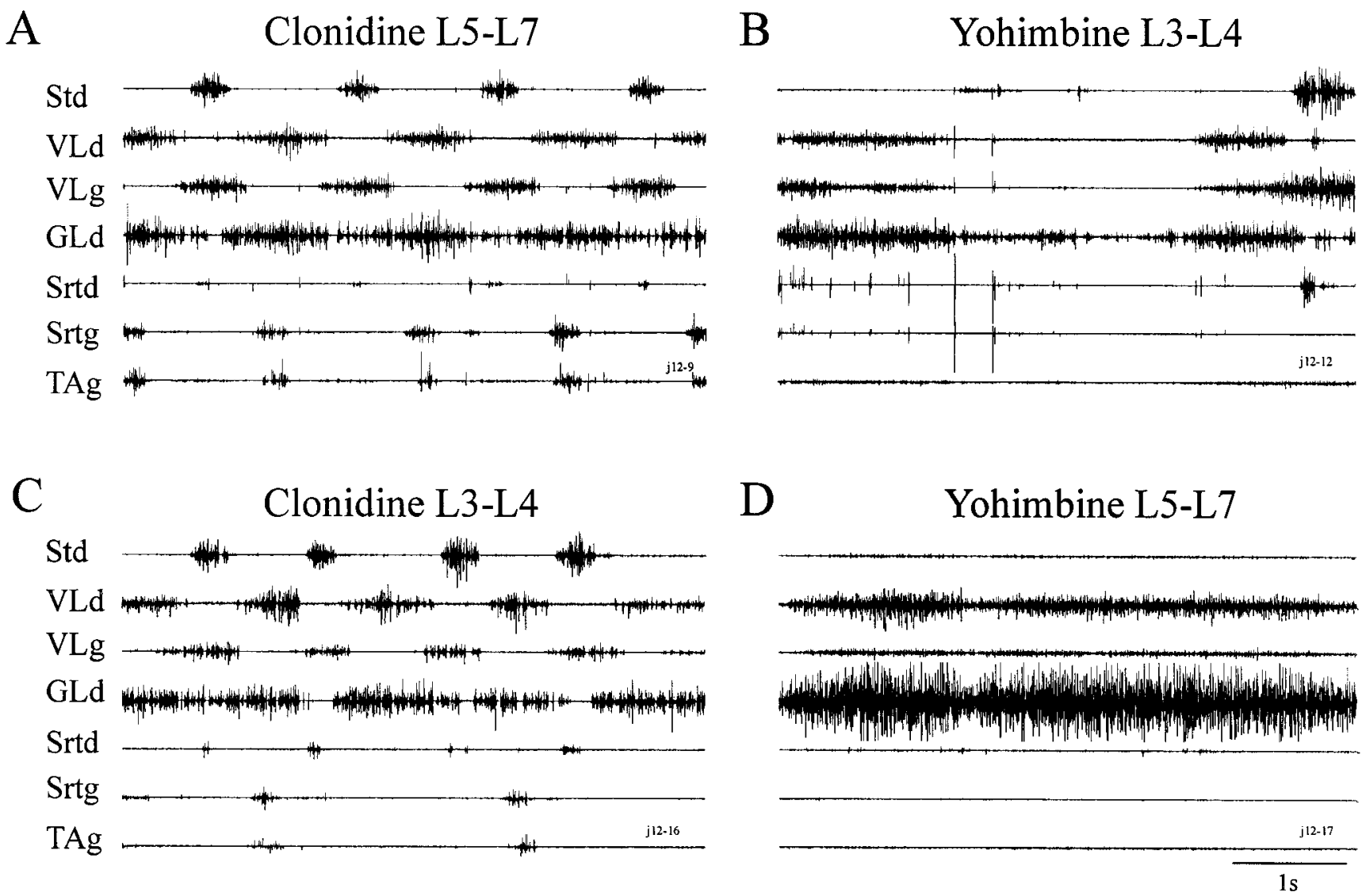

Figure 4. Interactions between segments L3-L4 and L5-L7. A, Hindlimb EMGs showing a regular rhythmic pattern with right-left and flexor-extensor alternation obtained $1 \mathrm{hr} 48 \mathrm{~min}$ after L5-L7 bath-applied clonidine $(5 \mathrm{mg} / \mathrm{ml})$. B, This pattern is lost within $15 \mathrm{~min}$ of the addition of yohimbine (16 $\mathrm{mg} / \mathrm{ml}$ ) in the L3-L4 bath; here it is illustrated at $23 \mathrm{~min}$. C, Hindlimb EMGs showing a similar rhythmic pattern along with a left-right and a flexor-extensor alternation after the application of clonidine $(5 \mathrm{mg} / \mathrm{ml})$ at L3-L4 bath after $2 \mathrm{hr}$. $D$, Again this pattern is lost with the addition of yohimbine $(16 \mathrm{mg} / \mathrm{ml}), 16 \mathrm{~min}$ after its application in the L5-L7 bath.

intraspinal injections, three cats never had any rhythmic activity with intraspinal clonidine or with clonidine injected intravenously afterward. One had locomotor activity only after intravenous L-DOPA but not after intraspinal or intravenous clonidine, and one did not show locomotor activity when receiving microinjections of clonidine but did when receiving clonidine intravenously.

\section{Yohimbine}

The effect of intraspinally injected yohimbine after the establishment of a locomotor pattern by intravenous clonidine was tested in six cats. In three cats, yohimbine was injected at L4 level and abolished the stepping pattern within 20-30 min of the last injection. Two of them also recovered their locomotor pattern after 1-2 $\mathrm{hr}$ of the last injection of yohimbine. One of those two was also tested with yohimbine injected only at L3 segment, and the rhythm was again disrupted. Figure $6 A$ shows the locomotor pattern elicited by intravenous clonidine, and Figure $6 B$ shows the disruption of the pattern by the injection of yohimbine at L4. In Figure $6 C, 2$ $\mathrm{hr}$ after yohimbine and a further injection of clonidine, the locomotor pattern was reinstated, and again it could be blocked by yohimbine injected locally at L3 (Fig. 6D).

L6 segment was microinjected with yohimbine in two cats. None of them had significant changes of their locomotion, even $>1 \mathrm{hr}$ after the injection. In one cat, microinjections of yohimbine were then made at L4 level and, this time, the rhythmic pattern was completely stopped from 15 min after the last injection until $1 \mathrm{hr} 15$ min. The same cat was afterward injected at L3 with yohimbine and, again, locomotor rhythm was disrupted from $15 \mathrm{~min}$ to $1 \mathrm{hr} 15$ min. The other cat, after microinjections in L6 segment had failed to stop locomotion, received injections in L5 segment that disrupted the locomotor pattern within $20 \mathrm{~min}$. Partial recovery after
$1 \mathrm{hr}$ was noticed. Microinjections of only L5 segment were also tried in one cat and resulted in permanent disruption of locomotor pattern.

\section{Additional spinal lesions}

To evaluate the importance of the rostral lumbar segments L3-L4 in the maintenance of spinal locomotion, we injected nine cats with clonidine intravenously and, when the locomotor pattern was clearly established, further spinal sections at the L3-L4 levels were performed. Figure 7 shows one of these cats that had developed a very good rhythmic pattern after intravenous clonidine. Some locomotor activity persisted after the L3 section, but it was much less organized. After a further section at L4, all rhythmic activity was lost. Nine cats received clonidine intravenously and sometimes L-DOPA intravenously (three of nine cats), and all had developed locomotor EMG activity and stepping. Six lost all rhythmic patterns after a section between L3 and L4, but three could still walk on the treadmill. The three cats lost all remaining locomotor ability when a final lesion was performed caudal to the last rootlet of L4. Therefore, none of the nine cats displayed any rhythmic activity when the cord was sectioned below L4, i.e., at the level of the most distal rootlet of L4. Note that we waited always $1 \mathrm{hr}$ after this last spinalization at L4 before reaching the conclusion that the cats could no longer walk. Furthermore, a supplementary dose of clonidine $(500 \mu \mathrm{g} / \mathrm{kg})$ and L-DOPA $(80 \mathrm{mg} / \mathrm{kg})$ was given to make sure that the arrest of locomotion was not caused by the fading effect of the drug.

\section{DISCUSSION}

We have shown that it is possible, in spinal cats, to initiate locomotor movements in all joints of both hindlimbs on a treadmill 
A

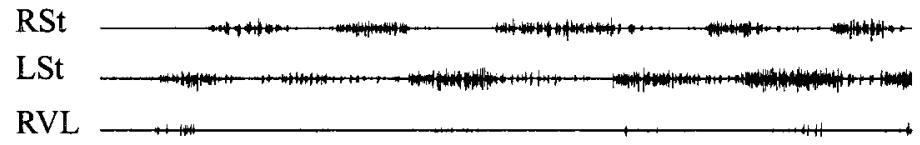

LVL

RGL

LGL

RSrt

LSrt

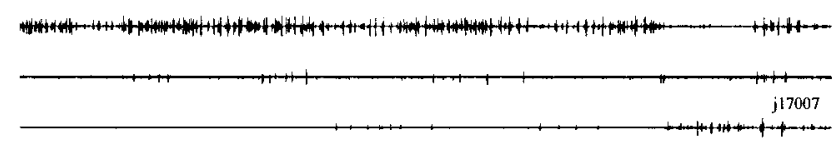

B

\section{micro-injection Clonidine L3-L4}

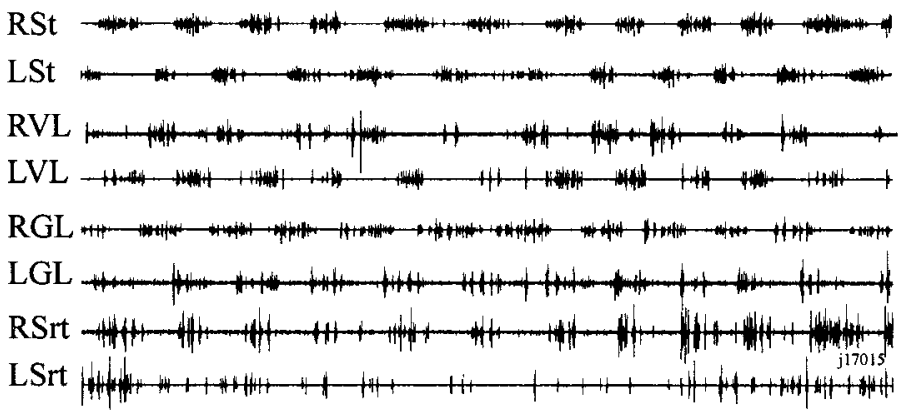

\section{i.v. injection Clonidine}

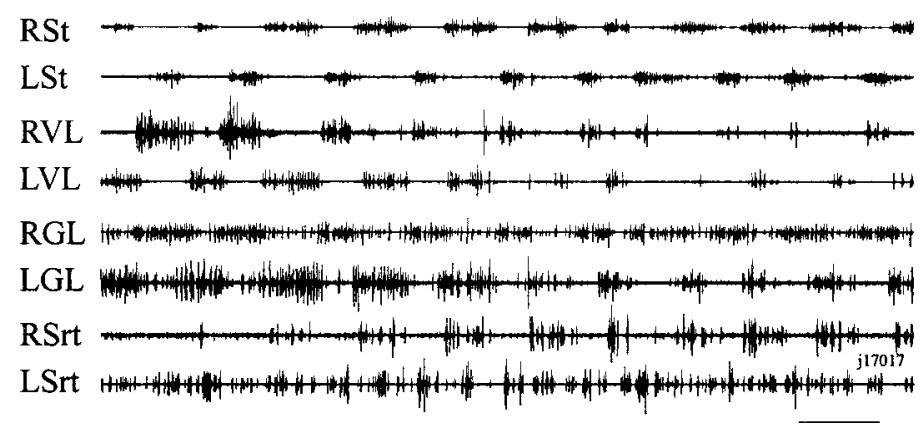

Is

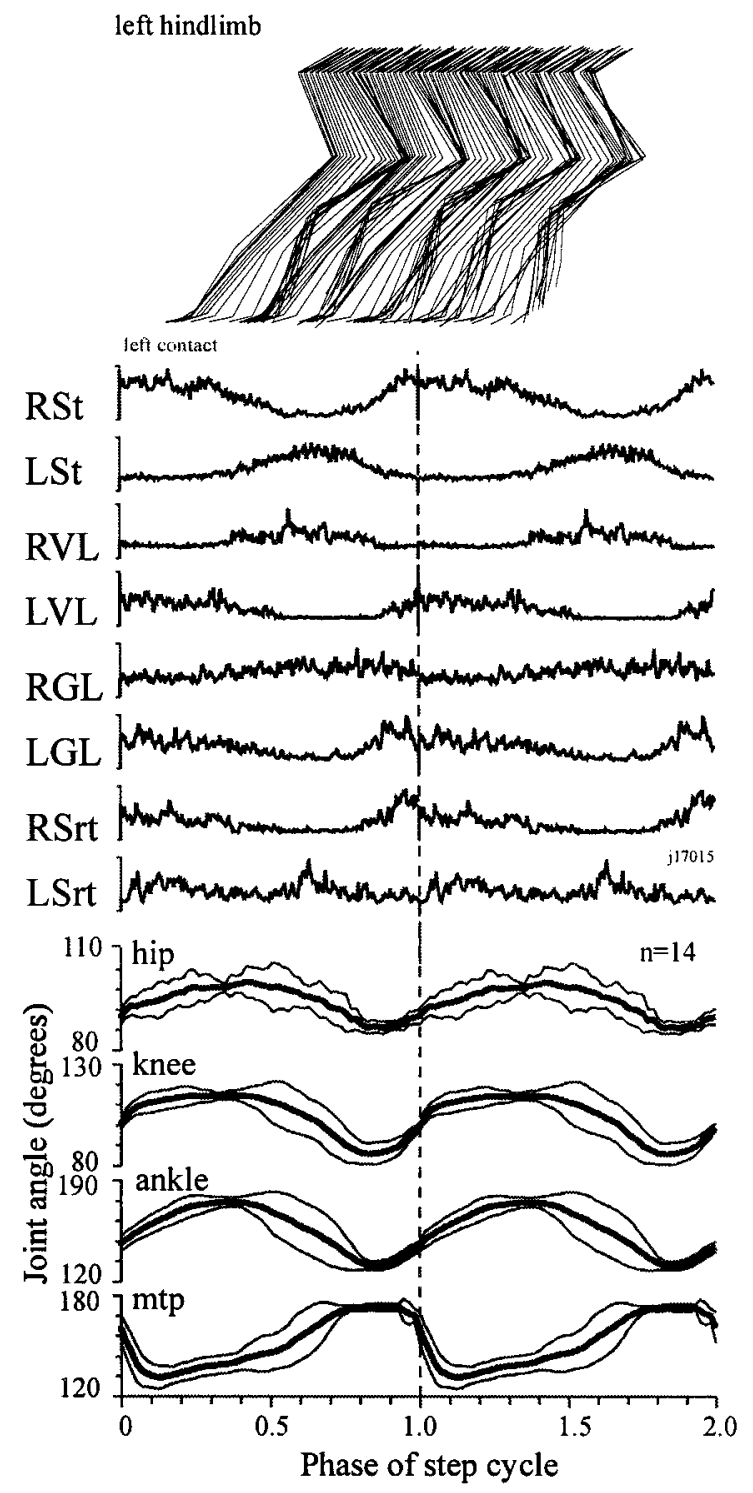

Figure 5. Intraspinal microinjections. $A$, Hindlimb EMGs 44 min after eight intraspinal injections of $2 \mu l$ each of clonidine $(10 \mathrm{mg} / \mathrm{ml})$ in the $\mathrm{L} 3 \mathrm{segment}$. $B$, Hindlimb EMGs of the same cat $2 \mathrm{hr}$ after the addition of eight injections of clonidine in the L4 segment. The rate of stepping is twice that after injection in L3 only. $B^{\prime}$, Top, The stick figures represent five consecutive cycles of the left hindlimb corresponding to the EMGs displayed in B. Middle, The rectified, normalized and averaged EMG recordings of a sequence of 14 steps sequence synchronized to left contact of the foot. Bottom, The averaged joint angular displacement (mean \pm SD) of hip, knee, ankle, and metatarsophalangeal joints for the same 14 normalized step cycles are also shown. $C$, Hindlimb EMGs of the same cat $9 \mathrm{~min}$ after intravenous clonidine $(500 \mu \mathrm{g} / \mathrm{kg})$ was added. The pattern is essentially the same of that displayed in $B$.

Table 2. Cycle and burst duration of locomotor sequences of the cat shown in Figure 5

\begin{tabular}{lcclllll} 
Clonidine & $n$ & $\begin{array}{l}\text { Cycle dura- } \\
\text { tion (msec) }\end{array}$ & $\begin{array}{l}\text { LSt dura- } \\
\text { tion (msec) }\end{array}$ & $\begin{array}{l}\text { LSt normalized } \\
\text { amplitude }\end{array}$ & $\begin{array}{l}\text { LVL dura- } \\
\text { tion (msec) }\end{array}$ & $\begin{array}{l}\text { LVL normalized } \\
\text { amplitude }\end{array}$ & $\begin{array}{l}\text { Interlimb } \\
\text { coupling }\end{array}$ \\
\hline Microinjection L3 & 7 & $1908 \pm 468$ & $995 \pm 238$ & $57 \pm 13$ & $419 \pm 266$ & $73 \pm 6$ & $0.52 \pm 0.13$ \\
Microinjection L3-L4 & 15 & $1053 \pm 208$ & $453 \pm 108$ & $51 \pm 4$ & $495 \pm 175$ & $69 \pm 22$ & $0.62 \pm 0.08$ \\
Intravenous injection & 47 & $969 \pm 119$ & $427 \pm 111$ & $56 \pm 18$ & $459 \pm 36$ & $81 \pm 22$
\end{tabular}

after applications of clonidine at restricted spinal segments. Stimulation confined to the rostral segments (L3-L4) could initiate rhythmic activity in muscles whose motoneurons are located in the L6-S1 lumbosacral segments. Furthermore, when the pattern was initiated at one level (L3-L4 or L5-L7), it could be blocked by yohimbine applied at another level (L5-L7 or L3-L4, respectively). Also, when clonidine (or L-DOPA) was injected intravenously, the induced locomotion could be blocked by a local injection of yohimbine at L3, L4, or L5. Finally, we showed that all cats made to walk with intravenous injection of this noradrenergic agonist stopped walking when the spinal cord was cut at caudal L4. We conclude that the network responsible for locomotion is distributed over several segments of the lumbar cord, that the overall pattern can be activated or blocked by stimulating or inactivating only discrete 
A i.v. injection Clonidine

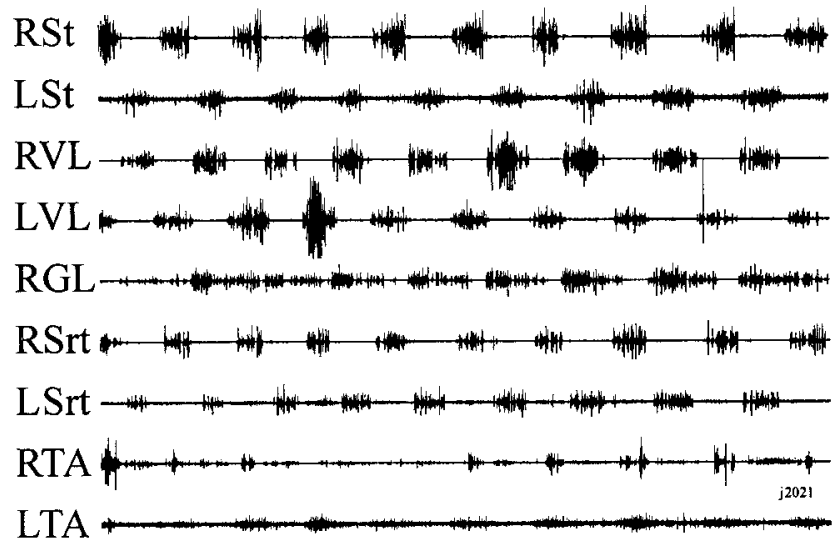

$\mathrm{C}$

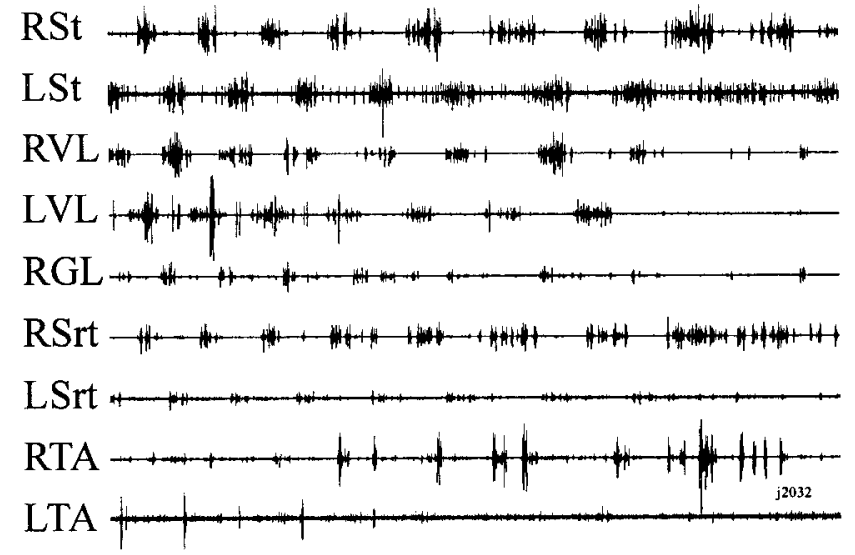

B after micro-injection Yohimbine L4

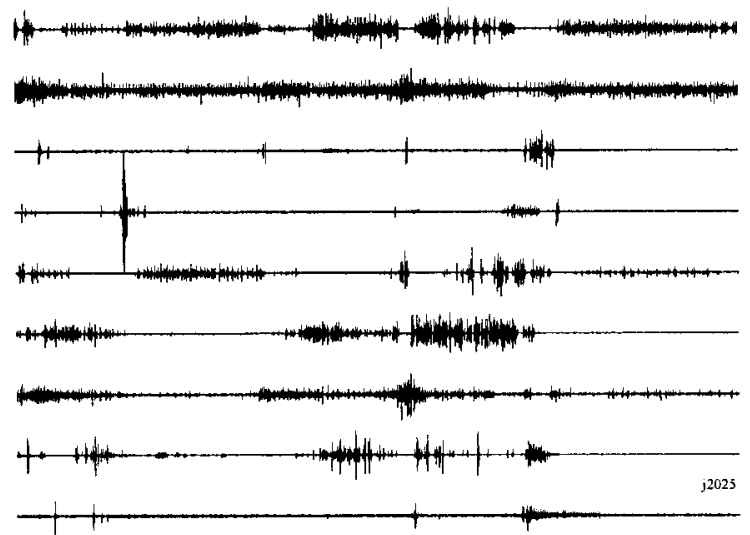

$\mathrm{D}$
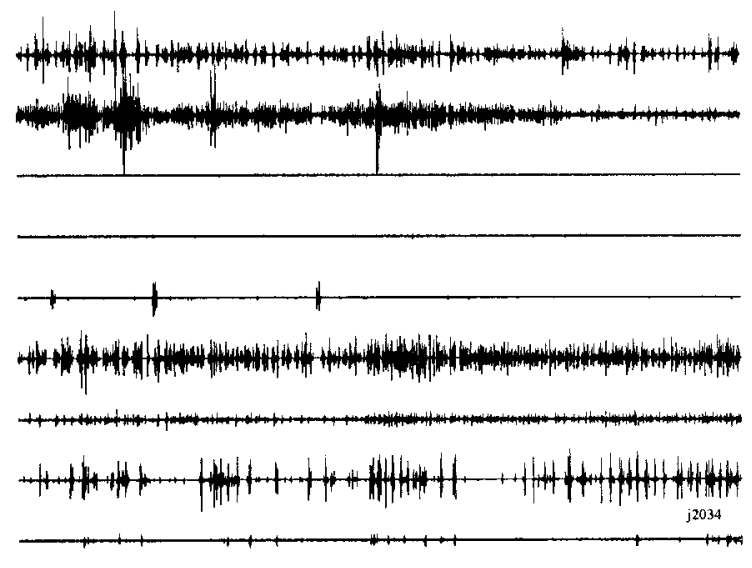

is

Figure 6. Initiation and block of locomotion by microinjections of noradrenergic drugs. $A$, Hindlimb EMG displaying a locomotor pattern 13 min after intravenous clonidine. $B$, Hindlimb EMG displaying only tonic activity $33 \mathrm{~min}$ after nine intraspinal injections of yohimbine $(8 \mathrm{mg} / \mathrm{ml})$ at L4 level and 1 $\mathrm{hr} 25 \mathrm{~min}$ after the injection of intravenous clonidine. C. Hindlimb EMGs of the same cat displaying the recovery of a locomotor pattern $2 \mathrm{hr}$ after the last injection of intraspinal yohimbine, $2 \mathrm{hr} 50 \mathrm{~min}$ after the first injection of intravenous clonidine and $23 \mathrm{~min}$ after the second. $D$, Hindlimb EMG again displaying tonic activity only $31 \mathrm{~min}$ after eight injections of yohimbine $(8 \mathrm{mg} / \mathrm{ml})$ at L3 level, $5 \mathrm{hr} 10 \mathrm{~min}$ after the first injection of intravenous clonidine, $2 \mathrm{hr} 40 \mathrm{~min}$ after the second, and $12 \mathrm{~min}$ after the third. RTA, Right tibialis anterior; $L T A$, left tibialis anterior.

parts of the network and finally, that the integrity of L3-L4 segments is necessary to maintain spinal locomotion.

\section{Methodological considerations}

We chose to test most of the cats 5-6 d after spinalization for several reasons. This eliminated the effects of spinal shock on the excitability of the cord at the time of the experiment and increased our chances of eliciting locomotion (Chau et al., 1998a) when the risk of spontaneous locomotion is low (Barbeau and Rossignol, 1987).

The hindlimb movements produced by our stimulation had the kinematics and EMG organization typical of locomotion. However, as seen in the early days after spinalization in chronic preparations, the stepping movements were not as elegant or as complete as those observed in a chronic, fully trained, spinal cat (Barbeau and Rossignol, 1991; Pearson and Rossignol, 1991). In our experiments, the movements were usually of smaller amplitude than that observed in the later stages, with the foot often landing on the dorsum during the stance phase. Also, the noxious stimulation provided by the spinal fixation and the laminectomy must have contributed to the incomplete expression of the locomotor pattern.

\section{Localization of spinal network for locomotion}

There have been numerous attempts to identify the spinal segments containing the network responsible for locomotion [central pattern generator (CPG)] in many species. In lower vertebrates, such as lamprey and dogfish, it has been shown that the ability to generate swimming is distributed along the spinal cord (Grillner, 1973; Grillner et al., 1991a,b). In the mudpuppy, some specialization exists among segments, and less than two segments are sufficient to produce locomotion in forelimbs (Wheatley et al., 1994). In the turtle, CPGs for different forms of scratch are distributed along the cord, but "key CPG elements reside in the anterior $60 \%$ of the hindlimb enlargement and in the segment just rostral to the enlargement" for all forms of scratch (Mortin and Stein, 1989). In the chick embryo, the capacity of rhythmic generation is present throughout the spinal cord and distributed in the ventral gray matter. However, a single segment is also able to generate rhythmic activities (Ho and O’Donovan, 1993).

Two different models have emerged from studies of neonatal rats. The work of Cazalets et al. (1995), with bath application of drugs, suggested that L1-L2 segments generate the locomotor rhythm. More caudal segments, containing motoneurons of hindlimb muscles (L3-L5), are considered the "follower segments." However, results of subsequent studies were inconsistent with this conclusion. For example, it was concluded (Kjaerulff and Kiehn, 1996) from lesion experiments that the ability to generate rhythmic patterns is not restricted to L1-L2 segments but rather distributed along lumbar and caudal thoracic segments even though the 
A

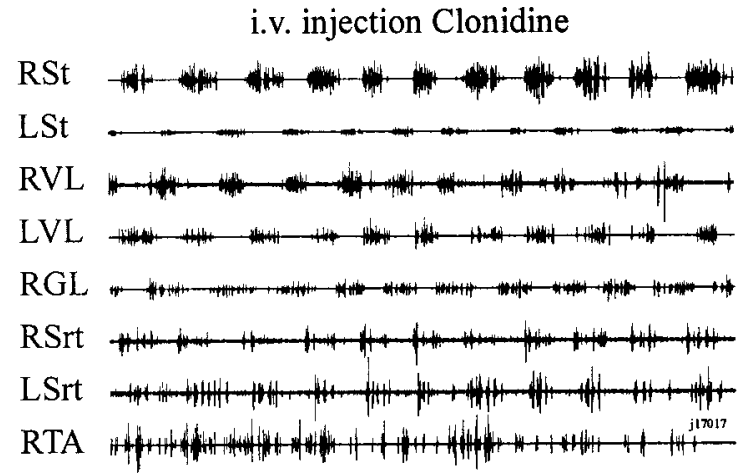

B

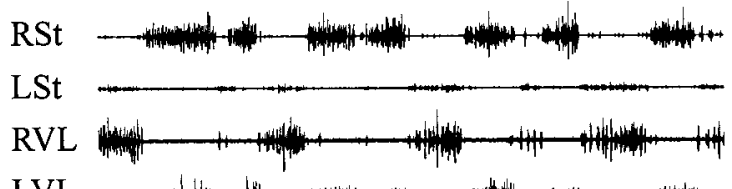

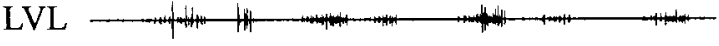
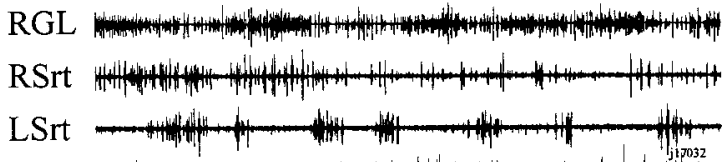

RTA H H +

C

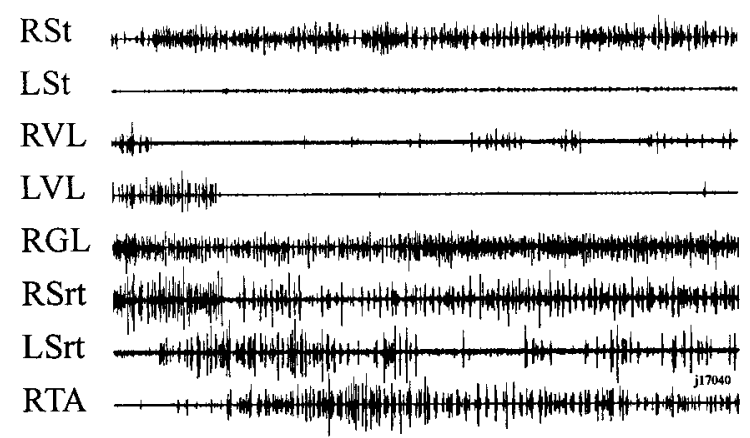

$1 \mathrm{~s}$

Figure 7. Effects of L3-L4 lesions on locomotion. A, Hindlimb EMGs 9 min after intravenous clonidine $(500 \mu \mathrm{g} / \mathrm{ml})$. B. Hindlimb EMGs $3 \mathrm{hr} 10$ min after the first intravenous clonidine injection, $1 \mathrm{hr}$ after the second injection (same dosage), and $2 \mathrm{hr} 30 \mathrm{~min}$ after the lesion at L3. Note that the rhythm slows down and loses its regularity. $C$, Hindlimb EMGs after three injections of clonidine ( $5 \mathrm{hr} 15 \mathrm{~min}, 3 \mathrm{hr} 5 \mathrm{~min}$, and $17 \mathrm{~min}$ before) and 1 hr $20 \mathrm{~min}$ after the additional lesion at L4. Only tonic activity is recorded.

T13-L2 segments are more prone to generate rhythms. A study of lesions made by kainic acid injections that destroyed gray matter but spared white matter showed that the destruction of gray matter at L2 resulted in severe paraparesia. This consequence was not observed when gray matter was destroyed at T9 level (Magnuson et al., 1999), suggesting that gray matter at rostral lumbar segments are crucial for locomotion. Others (Kremer and Lev-Tov, 1997) also proposed that locomotor rhythm generation was present from T12-T13 to L4 and showed that left-right alternation was even more widely distributed. Studies testing the serotonergic system (Cowley and Schmidt, 1997) showed that rhythm generation was possible in thoracic levels but not at L1-L2 segments and, most importantly, suggested that different networks could be activated depending on the drug used. Cazalets et al. (1995) obtained locomotion with 5-HT and NMDA, but 5-HT alone could not induce rhythmicity below T13 in Cowley and Schmidt (1997) experiments. We also have to take into account the different stages of development. Indeed, studies in neonatal mouse have shown that the ability of different spinal segments to generate spontaneous rhythms changes with time along the rostrocaudal axis (Bonnot et al., 1998).

Our results tend to concur with the idea that the locomotor network is distributed along lumbar segments because it was possible to induce stepping movements by stimulating either caudal lumbar segments or more rostral segments. Indeed, early experiments in cats have shown that, during fictive locomotion, rhythms could be evoked in ankle muscle nerves after a transection at rostral L5 (Grillner and Zangger, 1979), which corresponds to our caudal L4 section. Similar activities could have been present in our experiments but were obviously not sufficient to drive real stepping movements. Kremer and Lev-Tov (1997) reported rhythm generation after transection at L3 that was different and slower than before transection and after some time and when doubling the excitatory agent concentration (Deliagina et al., 1983). Cowley and Schmidt (1997) also reported rhythmic but nonlocomotor activity in L5 segment after transection at L3-L4 junction with NMDA. This is compatible with the notion of leading segments in midlumbar spinal cord and may explain why locomotion stopped after our L3 or L4 transections. Such sections did not damage the motor pools of hindlimb muscles because most of them are located in L5-S1 segments (Sherrington, 1892; Romanes, 1951); only the psoas minor portion of iliopsoas has its motoneurons situated mainly rostral to L5 (Vanderhorst and Holstege, 1997). In our experiments, it was especially interesting to see that injection of a very small amount of drug into L3-L4 segments alone could elicit a well organized locomotion, implicating muscles with motoneurons located well below the site of injection.

Which neuronal systems were involved in our stimulation? Obviously, neurons with noradrenergic receptors were activated by our injections, and the segmental distribution of these cells may not necessarily equal the distribution of all cells involved in central pattern generation. In neonatal rats, noradrenaline is more a modulator than an initiator of locomotion (Kiehn et al., 1999). However, the noradrenergic network appears to be crucial in initiating locomotion in early spinal cats (Barbeau and Rossignol, 1991), as it is for acute spinal monkeys (Fedirchuk et al., 1998), and there must be an intimate overlapping between the noradrenergic network and the CPG networks. If the segmental distribution of the noradrenergic receptors in the cat lumbar cord is known (Giroux et al., 1999), the exact laminar distribution is not yet known. We chose to inject at 2-mm-deep, corresponding to approximately half the thickness of the cord, and near the midline so the drug could reach two specific regions that are thought to contain neurons implicated in locomotor network: the intermediate gray matter (lamina VII) and lamina $\mathrm{X}$ around the central canal. Indeed, neurons in the intermediate gray matter were strongly labeled with $\left[{ }^{14} \mathrm{C}\right] 2$ deoxyglucose when locomotion was induced by drugs in rabbit at L6-S1 (Viala et al., 1988). The activity-dependent markers sulforhodamine in neonatal rat (Kjaerulff et al., 1994) and c-fos in cats (Dai et al., 1990) labeled neurons in lamina VI, VII, and X (Kiehn and Kjaerulff, 1998). Studies using intracellular recordings showed that neurons of lamina VII had rhythmic discharge during locomotor-like activity in neonatal rats (MacLean et al., 1995) or during scratching in cats (Berkinblit et al., 1978). Finally, a population of interneurons located at L4 in laminae VI-V II (Jankowska and Skoog, 1986) projecting monosynaptically to lumbar motoneurons in L6-L7 (Cavallari et al., 1987) that receives dominant input from group II afferents (mainly from sartorius and quadriceps) and from the mesencephalic locomotor region (MLR) (Edgley et al., 1988) was found rhythmically active during fictive locomotion (Shefchyk et al., 1990). This population is also contacted by descending noradrenergic systems (Maxwell et al., 2000) and could have been activated by our clonidine stimulation. MLR stimulation activates interneurons in the intermediate gray matter over all the lumbosacral cord of the cat but mainly at L4-L6 (Noga et al., 1995).

In conclusion, we propose that first, it is possible to induce locomotion in adult acutely spinalized cats with localized noradrenergic stimulation; second, segments rostral to the main motoneuron pools have the ability to generate locomotion as well as 
segments containing the main motoneuron pools; however, the lower segments containing motoneurons need the more rostral segments to maintain locomotion; and third, this distributed network can be inactivated at several levels.

\section{REFERENCES}

Armstrong DM (1986) Supraspinal contributions to the initiation and control of locomotion in the cat. Prog Neurobiol 26:273-361.

Barbeau H, Rossignol S (1987) Recovery of locomotion after chronic spinalization in the adult cat. Brain Res 412:84-95.

Barbeau H, Rossignol S (1991) Initiation and modulation of the locomotor pattern in the adult chronic spinal cat by noradrenergic, serotonergic and dopaminergic drugs. Brain Res 546:250-260.

Barbeau H, Julien C, Rossignol S (1987) The effects of clonidine and yohimbine on locomotion and cutaneous reflexes in the adult chronic spinal cat. Brain Res 437:83-96.

Berkinblit MB, Deliagina TG, Feldman AG, Orlovsky GN (1978) Generation of scratching. 1. Activity of spinal interneurons during scratching. J Neurophysiol 41:1040-1057.

Bonnot A, Morin D, Viala D (1998) Genesis of spontaneous rhythmic motor patterns in the lumbosacral spinal cord of neonate mouse. Dev Brain Res 108:89-99.

Bras H, Cavallari P, Jankowska E (1988) An investigation of local actions of ionophoretically applied DOPA in the spinal cord. Exp Brain Res 71:447-449.

Cavallari P, Edgley SA, Jankowska E (1987) Post-synaptic actions of midlumbar interneurones on motoneurones of hind-limb muscles in the cat. J Physiol (Lond) 389:675-689.

Cazalets J-R, Borde M, Clarac F (1995) Localization and organization of the central pattern generator for hindlimb locomotion in newborn rat. J Neurosci 15:4943-4951.

Chau C, Barbeau H, Rossignol S (1998a) Early locomotor training with clonidine in spinal cats. J Neurophysiol 59:392-409.

Chau C, Barbeau H, Rossignol S (1998b) Effects of intrathecal $\alpha_{1}$ - and $\alpha_{2}$-noradrenergic agonists and norepinephrine on locomotion in chronic spinal cats. J Neurophysiol 79:2941-2963.

Cowley KC, Schmidt BJ (1997) Regional distribution of the locomotor pattern-generating network in the neonatal rat spinal cord. J Neurophysiol 77:247-259.

Dai, X, Douglas JR, Nagy JI, Noga BR, Jordan LM (1990) Localization of spinal neurons activated during treadmill locomotion using the c-fos immunohistochemical method. Soc Neurosci Abstr 16:889.

de Leon RD, Hodgson JA, Roy RR, Edgerton VR (1998) Full weightbearing hindlimb standing following stand training in the adult spinal cat J Neurophysiol 80:83-91.

Deliagina TG, Orlovsky GN, Pavlova GA (1983) The capacity for generation of rhythmic oscillations is distributed in the lumbosacral spinal cord of the cat. Exp Brain Res 53:81-90.

Dimitrijevic MR, Gerasimenko Y, Pinter MM (1998) Evidence for a spinal central pattern generator in humans. Ann NY Acad Sci 860:360-376.

Edgerton VR, Roy RR, Hodgson JA, Prober RJ, de Guzman CP, de Leon R (1992) Potential of adult mammalian lumbosacral spinal cord to execute and acquire improved locomotion in the absence of supraspinal input. J Neurotrauma [Suppl 1] 9:S119-S128.

Edgley SA, Jankowska E, Shefchyk S (1988) Evidence that mid-lumbar neurones in reflex pathways from group II afferents are involved in locomotion in the cat. J Physiol (Lond) 403:57-71.

Fedirchuk R, Nielsen J, Peterson N, Hultborn H (1998) Pharmacologically evoked fictive motor patterns in the acutely spinalized marmoset monkey (Callithrix jacchus). Exp Brain Res 122:351-361.

Forssberg H, Grillner S (1973) The locomotion of the acute spinal cat injected with clonidine i.v. Brain Res 50:184-186.

Giroux N, Rossignol S, Reader TA (1999) Autoradoigraphic study of $\alpha_{1}$ and $\alpha_{2}$-noradrenergic and serotonin $_{1 \mathrm{~A}}$ receptors in the spinal cord of normal and chronically transected cats. J Comp Neurol 406:402-414.

Goldberg MR, Robertson D (1983) Yohimbine:A pharmacological probe for study of the $\alpha 2$-adrenoreceptor. Pharmacol Rev 35:143-180.

Grillner S (1973) Locomotion in the spinal cat. In: Control of posture and locomotion (Stein RB, Pearson KG, Smith RS, Redford JB, eds), pp 515-535. New York: Plenum.

Grillner S (1981) Control of locomotion in bipeds, tetrapods, and fish. In: Handbook of physiology. The nervous system II. (Brookhart JM, Mountcastle VB, eds), pp 1179-1236. Bethesda: American Physiology Society.

Grillner S, Zangger P (1979) On the central generation of locomotion in the low spinal cat. Exp Brain Res 34:241-261.

Grillner S, Wallen P, Brodin L, Lansner A (1991a) Neuronal network generating locomotor behavior in lamprey: circuitry, transmitters, membrane properties, and simulation. Annu Rev Neurosci 14:169-199.

Grillner S, Wallen P, Di Prisco GV (1991b) The lamprey locomotor system. In: Neurobiological basis of human locomotion (Shimamura M, Grillner S, Edgerton VR, eds), pp 77-92. Tokyo: Japan Scientific.

Ho S, O'Donovan J (1993) Regionalization and intersegmental coordination of rhythm-generating networks in the spinal cord of the chick embryo. J Neurosci 13:1354-1371.
Jankowska E, Skoog B (1986) Labelling of midlumbar neurones projecting to cat hindlimb motoneurones by transneuronal transport of a horseradish peroxidase conjugate. Neurosci Lett 71:163-168.

Jankowska E, Jukes MGM, Lund S, Lundberg A (1967a) The effect of DOPA on the spinal cord. 5. Reciprocal organization of pathways transmitting excitatory action to alpha motoneurones of flexors and extensors. Acta Physiol Scand 70:369-388.

Jankowska E, Jukes MGM, Lund S, Lundberg A (1967b) The effects of DOPA on the spinal cord. 6. Half centre organization of interneurones transmitting effects from the flexor reflex afferents. Acta Physiol Scand 70:389-402.

Kiehn O, Kjaerulff O (1998) Distribution of central pattern generators for rhythmic motor outputs in the spinal cord of limbed vertebrates. Ann NY Acad Sci 860:110-129.

Kiehn O, Hultborn H, Conway BA (1992) Spinal locomotor activity in acutely spinalized cats induced by intrathecal application of noradrenaline. Neurosci Lett 143:243-246.

Kiehn O, Sillar KT, Kjaerulff O, McDearmid JR (1999) Effects of noradrenaline on locomotor rhythm-generating networks in the isolated neonatal rat spinal cord. J Neurophysiol 82:741-746.

Kjaerulff O, Kiehn O (1996) Distribution of networks generating and coordinating locomotor activity in the neonatal rat spinal cord in vitro: a lesion study. J Neurosci 16:5777-5794.

Kjaerulff O, Barajon I, Kiehn O (1994) Sulforhodamine-labelled cells in the neonatal rat spinal cord following chemically induced locomotor activity in vitro. J Physiol (Lond) 478:265-273.

Kremer A, Lev-Tov A (1997) Localization of the spinal network associated with generation of hindlimb locomotion in the neonatal rat and organization of its transverse coupling system. J Neurophysiol 77:1155-1170.

MacLean JN, Hochman S, Magnuson DS (1995) Lamina VII neurons are rhythmically active during locomotor-like activity in the neonatal rat spinal cord. Neurosci Lett 197:9-12.

Magnuson DSK, Trinder TC, Zhang YP, Burke D, Morassutti DJ, Shields CB (1999) Comparing deficits following excitotoxic and contusion injuries in the thoracic and lumbar spinal cord of the adult rat. Exp Neurol 156:191-204.

Maxwell DJ, Riddell JS, Jankowska E (2000) Serotoninergic and noradrenergic axonal contacts associated with premotor interneurons in spinal pathways from group II muscle afferents. Eur J Neurosci 12:1271-1280.

Mortin LI, Stein PSG (1989) Spinal cord segments containing key elements of the central pattern generators for three forms of scratch reflex in the turtle. J Neurosci 9:2285-2296.

Noga BR, Fortier PA, Kriellaars DJ, Dai X, Detillieux GR, Jordan LM (1995) Field potential mapping of neurons in the lumbar spinal cord activated following stimulation of the mesencephalic locomotor region. J Neurosci 15:2203-2217.

Pearson KG, Rossignol S (1991) Fictive motor patterns in chronic spinal cats. J Neurophysiol 66:1874-1887.

Pollock LJ, Davis LE (1923) Studies in decerebration. I. A method of decerebration. Arch Neurol Psychiatry 10:391-398.

Romanes GJ (1951) The motor cell columns of the lumbo-sacral spinal cord of the cat. J Comp Neurol 117:387-398.

Rossignol S (1996) Neural control of stereotypic limb movements. In: Handbook of physiology, Section 12. Exercise: regulation and integration of multiple systems (Rowell LB, Sheperd JT, eds), pp 173-216. Oxford: American Physiological Society.

Rossignol S, Lund JP, Drew T (1988) The role of sensory inputs in regulating patterns of rhythmical movements in higher vertebrates. A comparison between locomotion, respiration and mastication. In: Neural control of rhythmic movements in vertebrates (Cohen A, Rossignol S, Grillner S, eds), pp 201-283. New York: Wiley.

Rossignol S, Chau C, Brustein E, Giroux N, Bouyer L, Barbeau H, Reader T (1998) Pharmacological activation and modulation of the Central Pattern Generator for locomotion in the cat. In: Neuronal mechanisms for generating locomotor activity (Kiehn O, Harris-Warrick RM, Jordan LM, Hulborn H, Kudo N, eds), pp 346-359.

Rossignol S, Bélanger M, Chau C, Giroux N, Brustein E, Bouyer L, Grenier C-A, Drew T, Barbeau H, Reader T (2000) The spinal cat. In: Neurobiology of spinal cord injury (Kalb RG, Strittmatter SM, eds), pp 57-87. Totowa, NJ: Humana.

Shefchyk S, McCrea DA, Kriellaars D, Fortier P, Jordan L (1990) Activity of interneurons within the L4 spinal segment of the cat during brainstemevoked fictive locomotion. Exp Brain Res 80:290-295.

Sherrington CS (1892) Notes on the arrangement of some motor fibres in the lumbo-sacral plexus. J Physiol (Lond) 13:621-772.

Vanderhorst VGJM, Holstege G (1997) Organization of lumbosacral motoneuronal cell groups innervating hindlimb, pelvic floor, and axial muscles in the cat. J Comp Neurol 382:46-76.

Viala D, Buisseret-Delmas C, Portal JJ (1988) An attempt to localize the lumbar locomotor generator in the rabbit using 2-deoxy-[14C]glucose autoradiography. Neurosci Lett 86:139-143.

Wheatley M, Jovanovic K, Stein RB, Lawson V (1994) The activity of interneurons during locomotion in the in vitro necturus spinal cord. J Neurophysiol 71:2025-2032. 